\title{
Biochemical adaptations in middle-distance runners: an assessment of blood and anthropometric parameters
}

\author{
Danila Di Majo, ${ }^{1}$ Gabriella Schiera, ${ }^{2}$ Valentina Contrò, ${ }^{3}$ Elena Joana Armeli, ${ }^{3}$ \\ Marcello Giaccone, ${ }^{3}$ Marco Giammanco, ${ }^{1}$ Marcello Traina, ${ }^{3}$ Antonio Palma, ${ }^{3}$ Patrizia Proia ${ }^{3}$ \\ ${ }^{1}$ Department of Legal, Social and Sports Sciences, University of Palermo; ${ }^{2}$ Department of Biological, \\ Chemical and Pharmaceutical Sciences and Technology, University of Palermo; ${ }^{3}$ Department of \\ Psychological, Educational and Training Sciences, University of Palermo, Italy
}

\begin{abstract}
In order to understand the mechanism underlying the physiological adaptation of purely aerobic workout, we investigated the effect of 2 months of training on nine males (17-22 year-old) middle distance running agonistic athletes. Blood sample was collected in the morning to analyze: hematological parameters, lipid profile, liver function enzymes [glutamate oxaloacetate transaminase, glutamate pyruvate transaminase, gamma-glutamyl transferase $(\gamma$-GT)] and skeletal and myocardial markers of muscle damage [creatin kinase (CK) and creatin kinase MB (CK-MB)]. Endurance training, as it implies high oxygen consumption, should increase reactive oxygen species, but it has been shown that exercise leads to increased activation of antioxidant defenses. In fact, serum levels of $\gamma$-GT enzyme and total CK were not increased. On the other hand, a statistical significant reduction of CKMB has been observed. There were not variations in hematological parameters. As far as the anthropometric value is concerned, after two months of training there was a change in weight $(\mathrm{P}<0.0001)$. Finally, any oxidative and biological stress was highlighted in the middle distance runners but, since this is a preliminary study, it would be of interest to replicate the study on a larger sample.
\end{abstract}

Correspondence: Patrizia Proia, Department of Psychological, Educational and Training Sciences, University of Palermo, via G. Pascoli, 90144 Palermo, Italy. Tel. +39.091.6236411 - Fax: +39.091.6236407.

E-mail: patrizia.proia@unipa.it

Key words: middle-distance runners, oxidative stress, CK-MB, biochemical parameters, body weight.

Conflict of interests: the authors declare no potential conflict of interests.

Received for publication: 17 September 2014.

Revision received: 15 October 2014.

Accepted for publication: 16 October 2014.

(C) Copyright D. Di Majo et al., 2014

Licensee PAGEPress, Italy

Journal of Biological Research 2014; 87:4713

doi:10.4081/jbr.2014.4713

This article is distributed under the terms of the Creative Commons Attribution Noncommercial License (by-nc 3.0) which permits any noncommercial use, distribution, and reproduction in any medium, provided the original author(s) and source are credited.

\section{Introduction}

Human body has several mechanisms to produce energy. Synthesis, degradation and removal of compounds constitute the metabolism of a subject. Sport requires a considerable metabolic adaptation to meet the increased energy demand, as well as the increased removal of metabolites. Furthermore, biological adaptation depends on type, intensity and duration of exercise. ${ }^{1,2}$ Studies on endurance athletes show typical biochemical changes in 12 to 24 $\mathrm{h}$ after exercise; in particular, they show an activity increase of lactate dehydrogenase and creatine kinase (CK) (MM and MB isoforms) enzymes.

Frequently, increased activity/concentration of some biochemical markers-damage related is not accompanied by significant changes in electrocardiogram or in athletic performance. This is illustrated by the fact that some players may have an increase of about 30 times CK activity after $24 \mathrm{~h}$ of stress without compromising performance and health. ${ }^{3,4}$ During physical activity, the high energy demand of muscles involves the consumption of a high volume of oxygen ${ }^{5}$ by the mitochondrial respiratory chain.$^{6-8}$ The acute physical exercise leads to a high oxidative stress condition characterized by an imbalance between the pro-oxidants and antioxidants species. ${ }^{9}$ Oxidative stress from exercise is linked to the phenomenon of muscle fatigue, which results in an increase in the accident rate and a reduction of recovery time. ${ }^{10}$ Several studies have shown that endurance activities - especially in untrained subjects - produces oxidative substances. ${ }^{11,12}$ In particular, reactive oxygen species increase levels of lipid peroxidation in cell membranes leading to a decrease in cell membrane fluidity. ${ }^{2}$

Depending on how it is carried out, physical activity may be considered as a tool of disease prevention. ${ }^{13-15}$ The correct practice of sport activities improves life's quality and reduces morbidity and mortality of various pathologies. Physical activity have shown many benefits on cardiovascular disease risk factors, but in which way it helps to control weight, condition the heart muscle and moderate stress, is not clear enough. Endurance training seems to be more effective than any other type of training in decreasing fat mass, resting heart rate and lower blood pressure: it has a greater impact on maximum oxygen uptake and it more effectively reduces cardiovascular disease risk factors.

The purpose of the present investigation is to compare baseline hematological parameters and biochemical value after two months of moderate aerobic training in nine non-professional males. In particular, we aim to examine the possible beneficial effects of aerobic exercise on hematological parameters, lipid profile, liver function enzymes and markers of muscle damage. 


\section{Materials and Methods}

Nine male professional middle-runners, $19 \pm 3$ year-old and $175.7 \pm 6.4 \mathrm{~cm}$ high, were enrolled. During the entire training period and about every two days, the athletes took a mineral salts integrator containing potassium aspartate and magnesium aspartate due to high temperatures and humidity. During the two months of training athletes had no injuries.

The middle runners have different aerobic and anaerobic capabilities than sprinters and long distance runners. Athletes were monitored from August 2012 to the end of September 2012. We chose this period because it has the purpose to improve the functional capabilities of the organism and the training does not focus on achieving a specific physical form. Furthermore, the athletes were willing to partecipate to our study because that period did not include any race and it was not particularly stressfull for them. During this period, they carried out an aerobic-anaerobic workout (75\% aerobic and 25\% anaerobic); they trained 10 times per week for $60 \mathrm{~min}$, with a double session for 4 days/week and a single session for 2 days/week. Each session included a warm-up and cool-down period involving $20 \mathrm{~min}$ of low-intensity walking and light stretching activities. Athletes follow an aerobic/anaerobic (lactacid) protocol that included slow, middle and fast fund, strides and jog sat race speed.

Blood sample was collected by a clinical specialized center in the morning after overnight fast in order to analyze: glutamate oxaloacetate transaminase (GOT), glutamate pyruvate transaminase (GPT), gamma glutamyltransferase ( $\gamma$-GT), CK and CK-MB, as well as lipid profile [triglycerides, total cholesterol (CHOL-t), high density lipoproteincholesterol (HDL-c), low density lipoprotein-cholesterol (LDL-c)] and hematological parameters [hemoglobin (HGB), hematocrit (HCT), red blood cells (RBC), white blood cells (WBC; neutrophils, lymphocytes, monocytes, eosinophils, basophils, platelets]. All values are shown in Tables 1, 2 and 3 . Changes in the variables from pre- to post-race were analyzed with Student's $t$-test for paired samples. $\mathrm{P}<0.05$ on a twotailed test was considered as statistically significant. This statistical analysis was performed using GraphPad software.

\section{Results}

We investigate the effect of two months of training on middle distance running (800 and 1500 meters) on athletes. The physiological characteristics of middle runners are different from those of sprinters and long distance runners because include a variety of aerobic and anaerobic capabilities. Before and after the training period blood analysis was done in order to evaluate the adaptation of a purely aerobic workout. Cardio-vascular risk factors, blood cell counts and serum enzymes are reported in Tables 1, 2 and 3 . As showed in Table 1, body weight was significantly reduced $(\mathrm{P}<0.0001)$, while lipid profile, $\mathrm{CHOL}-$ t, HDL-c, LDL-c, triglycerides as well as liver function correlated enzymes (GOT, GPT, GT) were unchanged. As previously described by Kraus and colleagues, ${ }^{16}$ it is the amount of activity and not necessarily the intensity that is important for the improvement of the lipoprotein profile with exercise programs. Futhermore, during the early stage of training (3 months) they observed a slightly increase in cholesterol level, which starts to decrease after six months and when there is much and a high intensity activity. We were in the period of pre-season training that is just two months, so too short to see a decrease in lipid profile. Markers of muscle damage had a different trend; both total CK and CK-MB decreased but only the latter in a statistically significantly manner $(\mathrm{P}<0.0173)$. As regards the hematological parameters, the level remained unchanged after training time. In any case, all parameters kept in a physiological range.

\section{Discussion}

There are numerous reports published on the effects of endurance sports such as the 5000 or $10,000 \mathrm{~m}$, but a few investigations addressed hematological and biochemical changes after middle distance running (800 and $1500 \mathrm{~m}) .{ }^{17,18}$ The aim of this study was to investigate the possible beneficial effects of aerobic training on blood chemical, particularly on serum activity enzymes and hemocytometric test. Regarding lipid profile, we observed a little difference in baseline levels and after two months of training in all parameters. As regard triglycerides levels, there was a decrease after the investigation. This could be a consequence of starting to use body fat as major energy source instead of carboidrates. ${ }^{19}$ Body weight decrease $(\mathrm{P}<0.0001)$ after training was probably due to the type of aerobic exercise performed. We checked also serum enzyme activity; some of those are particularly correlated with liver function (GOT, GPT and GT) and the others are mainly related with muscular injury (CK and CK-MB). As regards GOT and GPT, there was an important decrease but not in a significant manner. This is probably due to the short term of training. Gamma glutamyl transferase remained unchanged until the end of training; this means that there was no implication of damage to the skeletal muscle and hepatic cells. Moreover, $\gamma$ GT is usually correlated with oxidative stress since it is involved in metabolizing extracellular glutathione which protects cells from oxidative stress by reacting with hydrogen peroxide. ${ }^{20}$ To emphasize this results there is also the change in CK and CK-MB value; in fact, we found a decrease both of CK and CK-MB, but more in the latter $(\mathrm{P}<0.0173)$. This means that there was a rapid adaption in cardiac muscle but also in skeletal muscle since level decrease in a significant manner. Usually these parameters have been generally considered to be an indirect marker of muscle damage (skeletal and myocardial). However, there is controversy in the literature concerning its validity in reflecting muscle damage as a consequence of level and intensity of physical exercise. ${ }^{21}$

Table 1. Change in weight and lipid profile related to lipid metabolism.

\begin{tabular}{|c|c|c|c|c|}
\hline Variables & & Pre-training & Post-training & $\mathbf{P}$ \\
\hline Weight (kg) & & $59.3 \pm 5.1$ & $58.1 \pm 4.9$ & $<0.0001$ \\
\hline Lipid profile (mg/dL) & $\begin{array}{l}\text { GT } \\
\text { CHOL-t } \\
\text { HDL-c } \\
\text { LDL-C }\end{array}$ & $\begin{array}{c}85.5 \pm 24.9 \\
155.5 \pm 23.3 \\
64.8 \pm 10.6 \\
73.5 \pm 19.3\end{array}$ & $\begin{array}{c}75.2 \pm 12.2 \\
163.6 \pm 43.4 \\
60.6 \pm 13.3 \\
87.9 \pm 32.5\end{array}$ & $\begin{array}{l}\text { ns } \\
\text { ns } \\
\text { ns } \\
\text { ns }\end{array}$ \\
\hline
\end{tabular}

GT, glutamyltransferase; CHOL-t, total cholesterol; HDL-c, high density lipoprotein-cholesterol; LDL-c, low density lipoprotein-cholesterol; ns, not significant. Values are expressed as mean \pm standard deviation. 
Table 2. Serum enzymes activity.

\begin{tabular}{|c|c|c|c|}
\hline Variables (U/L) & Pre-training & Post-training & $\mathbf{P}$ \\
\hline GOT & $23.5 \pm 6.05$ & $19.88 \pm 3.21$ & ns \\
\hline GPT & $19.8 \pm 3.2$ & $18.1 \pm 8.5$ & ns \\
\hline$\gamma \mathrm{GT}$ & $18.2 \pm 4.5$ & $18.1 \pm 4.0$ & ns \\
\hline CK & $183.4 \pm 85.9$ & $130.8 \pm 30.6$ & ns \\
\hline CK-MB & $24.6 \pm 5.6$ & $19.8 \pm 4.4$ & $<0.0173$ \\
\hline
\end{tabular}

GOT, glutamate oxaloacetate transaminase; GPT, glutamate pyruvate transaminase; $\gamma \mathrm{GT}$, gamma glutamyltransferase; CK, creatin kinase; CK-MB, creatin kinase MB; ns, not significant. Values are expressed as mean \pm standard deviation.

Table 3. Hematological parameters.

\begin{tabular}{lccc}
\hline Variables & Pre-training & Post-training \\
RBC $\left(10^{\wedge} 3 / \mu \mathrm{L}\right)$ & $5.0 \pm 0.3$ & $5.0 \pm 0.3$ & $\mathrm{~ns}$ \\
$\mathrm{HGB}(\mathrm{g} / \mathrm{dL})$ & $14.4 \pm 0.9$ & $14.5 \pm 1.0$ & $\mathrm{~ns}$ \\
\hline $\mathrm{HCT}(\mathrm{g} / \mathrm{dL})$ & $42.7 \pm 2.0$ & $44.05 \pm 2.3$ & $\mathrm{~ns}$ \\
WBC $\left(10^{\wedge} 3 / \mu \mathrm{L}\right)$ & $6.1 \pm 1.2$ & $6.0 \pm 1.3$ & $\mathrm{~ns}$ \\
\hline Neutrophils $\left(10^{\wedge} 3 / \mu \mathrm{L}\right)$ & $2.7 \pm 0.7$ & $2.7 \pm 0.7$ & $\mathrm{~ns}$ \\
Lymphocytes $\left(10^{\wedge} 3 / \mu \mathrm{L}\right)$ & $2.5 \pm 0.5$ & $2.6 \pm 0.4$ & $\mathrm{~ns}$ \\
\hline Monocytes $\left(10^{\wedge} 3 / \mu \mathrm{L}\right)$ & $0.57 \pm 0.3$ & $0.51 \pm 0.3$ & $\mathrm{~ns}$ \\
Eosinophils $\left(10^{\wedge} 3 / \mu \mathrm{L}\right)$ & $0.19 \pm 0.09$ & $\mathrm{~ns}$ & $\mathrm{~ns}$ \\
\hline Basophils $\left(10^{\wedge} 3 / \mu \mathrm{L}\right)$ & $0.01 \pm 0.01$ & & $\mathrm{~ns}$ \\
Platelet $\left(10^{\wedge} 3 / \mu \mathrm{L}\right)$ & $199.2 \pm 36.4$ & $0.01 \pm 0.009$ & \\
\hline
\end{tabular}

RBC, red blood cells; HGB, hemoglobin; HCT, hematocrit; WBC, white blood cells; ns, not significant. Values are expressed as mean \pm standard deviation.

\section{Conclusions}

This study establishes a low impact of this kind of training particularly on skeletal and cardiac muscles as well as on oxidative stress. Red blood cells, HGB and HCT - three indicators of anemia - were normal before and after training, as well as WBC. The change in platelets number was inconsistent with previous studies. One caveat is that the range of observation probably was too short t 0 enhance several changes in all indicators. Since this is a pilot study, it will be of interest to extend it to a big group, possibly for a longer time, and to compare with athletes from other sports, also by increasing the number of subjects that are involved in the protocol.

\section{References}

1. Monteiro WD, Araújo CGS. Transição caminhada-corrida: consideraçõ es fisiológicas e perspectivas para estudos futuros. Rev Bras Med Esporte 2001;7:207-22.

2. Egermann M, Brocai D, Lill CA, Schmitt H. Analysis of injuries in long-distance triathletes. Int J Sports Med 2003;24:271-6.

3. Apple FS, Rogers MA, Ivy JL. Creatine kinase isoenzyme MM variants in skeletal muscle and plasma from marathon runners. Clin Chem 1986;32:41-4.

4. Clarkson PM, Hubal MJ. Exercise-induced muscle damage in humans. Am J Phys Med Rehab 2002;81:52-69.

5. Keul J, Doll E. Oxidative energy supply. In: Jokl E, ed. Energy metabolism of human muscle. Baltimore, MD: University Park Press; 1972. pp 52-202.
6. Davies KJ, Quintanilha AT, Brooks GA, Packer L. Free radicals and tissue damage produced by exercise. Biochem Bioph Res Co 1982;107:1198-205.

7. Alessio HM. Exercise-induced oxidative stress. Med Sci Sport Exer 1993;25:218-24.

8. Kanter MM. Free radicals, exercise, and antioxidant supplementation. Int J Sport Nutr 1994;4:205-20.

9. Shindoh C, Di Marco A, Thomas A, et al. Effect of nacetylcysteine on diaphragm fatigue. J Appl Physiol 1990;68:2107-13.

10. Sanchez-Quesada JL, Homs-Serradesanferm R, Serrat-Serrat J, et al. Increase of LDL susceptibility to oxidation occurring after intense, long duration aerobic exercise. Atherosclerosis 1995;118:297-305.

11. Tappel AL. Lipid peroxidation damage to cell components. Fed Proc 1973;32:1870-4.

12. Esterbauer H, Zollner H. Methods for determination of aldehydic lipid peroxidation products. Free Radical Bio Med 1995;7:197-203.

13. Reid MB, Haack KE, Franchek KM, et al. Reactive oxygen in skeletal muscle. I. Intracellular oxidant kinetics and fatigue in vitro. J Appl Physiol 1992;73:1797-804.

14. Reid MB. Free radicals and muscle fatigue: of ROS, canaries, and the IOC. Free Radical Bio Med 2008;44:169-79.

15. Sureda A, Ferrer MD, Tauler P, et al. Effects of exercise intensity on lymphocyte $\mathrm{H} 202$ production and antioxidant defences in soccer players. Brit J Sport Med 2009;43:186-90.

16. Kraus WE, Houmard JA, Duscha BD, et al. Effects of the amount and intensity of exercise on plasma lipoproteins. New Engl J Med 2002;347:1483-92.

17. Nagel D, Seiler D, Franz H. Biochemical, hematological and endocrinological parameters during repeated intense short-term 
running in comparison to ultra-long-distance running. Int J Sports Med 1992;13:337-43.

18. Thompson PD, Crouse SF, Goodpaster B, et al. The acute versus the chronic response to exercise. Med Sci Sport Exer 2001;33:438-45.

19. Paoli A, Pacelli QF, Moro T, et al. Effects of high-intensity circuit training, low-intensity circuit training and endurance training on blood pressure and lipoproteins in middle-aged overweight men. Lipids Health Dis 2013;12:131.
20. Nakagawa $\mathrm{H}$, Isogawa A, Tateishi R, et al. Serum gamma-glutamyl transferase level is associated with serum superoxide dismutase activity and metabolic syndrome in a Japanese population. J Gastroenterol 2012;147:187-94.

21. Baird MF, Graham SM, Baker JS, Bickerstaff GF. Creatine kinase and exercise-related muscle damage implications for muscle performance and recovery. J Nutr Metab 2012;1:1-14. 